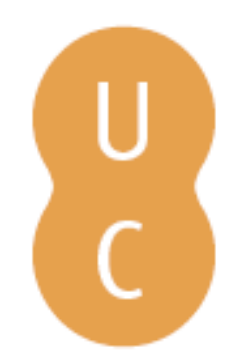

\title{
pompalina
}

\section{El término tragicomedia en el drama humanístico}

\author{
Autor(es): $\quad$ Rincón González, María Dolores
}

Publicado por: Centro de Estudos Clássicos e Humanísticos da Universidade de

URL

persistente: URI:http://hdl.handle.net/10316.2/30279

DOI: $\quad$ DOI:http://dx.doi.org/10.14195/978-989-721-038-9_50

Accessed : $\quad$ 26-Apr-2023 14:00:31

A navegação consulta e descarregamento dos títulos inseridos nas Bibliotecas Digitais UC Digitalis, UC Pombalina e UC Impactum, pressupõem a aceitação plena e sem reservas dos Termos e Condições de Uso destas Bibliotecas Digitais, disponíveis em https://digitalis.uc.pt/pt-pt/termos.

Conforme exposto nos referidos Termos e Condições de Uso, o descarregamento de títulos de acesso restrito requer uma licença válida de autorização devendo o utilizador aceder ao(s) documento(s) a partir de um endereço de IP da instituição detentora da supramencionada licença.

Ao utilizador é apenas permitido o descarregamento para uso pessoal, pelo que o emprego do(s) título(s) descarregado(s) para outro fim, designadamente comercial, carece de autorização do respetivo autor ou editor da obra.

Na medida em que todas as obras da UC Digitalis se encontram protegidas pelo Código do Direito de Autor e Direitos Conexos e demais legislação aplicável, toda a cópia, parcial ou total, deste documento, nos casos em que é legalmente admitida, deverá conter ou fazer-se acompanhar por este aviso.

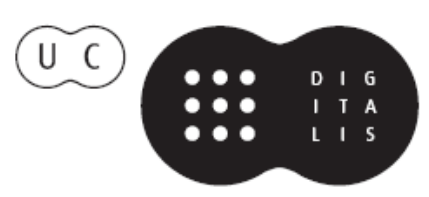




\section{De ayer a hoy}

\section{Influencias clásicas en la literatura}

\section{Aurora López, Andrés Pociña, Maria de Fátima Silva (coords.)}




\title{
El TÉRMINO TRAGICOMEDIA EN EL DRAMA HUMANíSTICO
}

\author{
María Dolores Rincón González \\ Universidad de Jaén
}

\begin{abstract}
Desde mediados del s. XV, la ausencia del texto aristotélico sobra la comedia, la ampliación del número de piezas conocidas de Plauto, el descubrimeinto de códices con las comedias terencianas precedidas del Comentum Donati, y el interés docente y cortesano por las representaciones dramáticas y los espacios arqueológicos, suscitaron preguntas teóricas sobre la estructura, forma y representación del teatro antiguo, y las características del drama humanístico. Una lectura crítica de las praefationes de los dramas del italiano C. Verardi (1440-1500) nos brinda argumentos al respecto y nos ayuda a comprender, a partir de Plauto, el uso del término tragicomedia presente en el título de la Celestina.
\end{abstract}

Desde mediados del s. XV el interés por el teatro antiguo fue en aumento entre mecenas, escritores, y arquitectos en la mayor parte de los centros culturales europeos y de manera especial en Italia. El interés recaía en gran medida sobre la comedia, género del que se disponía de pocas bases teóricas dada la ausencia de un texto aristotélico específico similar al de la tragedia.

El afán por discernir las normas que regían en el texto dramático de la comedia antigua, y todo lo relacionado con su puesta en escena, se vio potenciado con la ampliación del número de piezas conocidas de Plauto y el descubrimiento de nuevos códices con las comedias de Terencio precedidas del Comentum Donati, circunstancias que coincidían con la actividad docente y cortesana relacionada con las representaciones de ambiente profano y el reencuentro, de carácter anticuario, con espacios y restos arqueológicos hasta el momento escasamente percibidos. Entre los escritores italianos de finales del quattrocento y el cinquecento a menudo se suscitaron preguntas teóricas sobre la estructura, forma y representación del teatro antiguo al mismo tiempo que se proponían pautas sobre lo que habría de ser el drama humanístico.

Los comentarios de Donato a Terencio y los praenotamenta de autores recentiores (Guido Iuvenalis,Johannes Calphurnius, Badio Ascensio, entre otros), junto con las ediciones ilustradas de sus comedias formaron un corpus liminar del que surgiría, por amalgama y síntesis, la teoría de la comedia a mediados del s. XVI. Hemos de añadir a este corpus algunos planteamientos teóricos no sistematizados en textos preliminares de ciertas piezas teatrales de finales del s. XV y comienzos del s. XVI, en los que es posible extraer la problemática al respecto como ocurre en las praefationes de dos dramas del italiano C. Verardi de Cesena, en donde su autor, a partir de Plauto, brinda argumentos que nos 
ayudan a conocer la justificación del uso del término tragicomedia como modo de definir la naturaleza híbrida de sus dramas precisamente en un momento en el que no existía una teoría de la comedia propiamente dicha y se ensayaba un modo de imitación a partir de un conocimiento impreciso y confuso con el que se pretendía intuir y reconstruir el tratado aristotélico inexistente.

En este sentido cabe afirmar que el desarrollo del teatro humanístico del s. XV planteó cuestiones claves para la cultura de su tiempo, como sucede con el concepto de imitación de los modelos clásicos, la autonomía y originalidad de los textos particulares, la dependencia del mundo contemporáneo o las propuestas sobre la representación misma. A partir de la segunda mitad del s. XV el interés por la representación de comedias clásicas, y también contemporáneas, contrasta de manera especial con la situación anterior más proclive a la lectura de los textos como auténticas exercitationes de los propios autores.

El italiano C. Verardi (c. 1440-1500) como autor dramático se inscribe en este contexto. Fue secretario de cartas latinas de cuatro Pontífices: Paulo III, Sixto IV, Inocencio VIII, Alejandro VI. Curial muy vinculado al círculo hispanófilo de Roma, en el que se desenvolvieron los cardenales Pietro y Raphaele Riario, B. López de Carvajal, J. Ruiz de Medina, la familia Borja, etc. En sintonía con los objetivos de aquellos personajes, escribió dos piezas teatrales motivadas por dos acontecimientos españoles de 1492: la toma de Granada y el atentado del rey Fernando en Barcelona. Aquellas piezas se titularon: Historia Baetica y Fernandus servatus. Fueron escritas casi de manera simultánea a los acontecimientos y representadas con la misma inmediatez en abril del mismo año y en el mismo mes al año siguiente. El éxito de la representación y la oportunidad política de su divulgación son la clave de una abundancia editorial poco usual en composiciones de tal tipo. Abundancia editorial a la que se incorporaron las imprentas de Salamanca y Valladolid con aportación de sendas ediciones de incunables (1494 y 1497).

Sin embargo, a pesar del éxito en su momento, no se ha destacado lo suficiente su aportación a las bases previas al desarrollo de la teoría moderna de la comedia. En opinión de L. Cabranes-Grant, el uso del término tragicomedia ha de ser valorado como "hallazgo central para el desarrollo del teatro moderno" 1 . Previamente M. Menéndez Pelayo puso de relieve su conexión con el segundo título de la Celestina al afirmar de manera rotunda: Me parece fuera de duda que Fernando de Rojas conocía la obra de Verardo, que por su asunto debió de divulgarse bastante en España, y quizá la lectura de su prólogo le sugirió la idea de cambiar el título de Comedia que habia dado a la Celestina en tragicomedia.

\footnotetext{
${ }^{1}$ Cabranes-Grant, L., "La resistencia a la Tragicomedia: Giraldi Cintio y una polémica sobre Celestina”, Celestinesca 22, 1 (1998).
} 
Obsérvese también que la explicación que da del nombre conviene con la de Verardo y no con la de Plauto. Pero puede admitirse la influencia simultánea de los dos textos. Tengo por seguro que la Celestina estaba escrita antes del Fernandus Servatus, pero en su primitiva forma no se llamaba tragicomedia, sino comedia ${ }^{2}$.

La expresión la usa explícitamente Verardi en la praefatio del Fernandus servatus, en donde leemos: Potest enim haec nostra, ut Amphitruonem suum Plautus appellat, Tragicomoedia nuncupari: quod personarum dignitas et regiae maiestatis impia illa violatio ad tragoediam, iucundus vero exitus rerum ad comoediam pertinere videantur ${ }^{3}$. El término híbrido se justifica a partir de la definición habitual de los géneros de la tragedia y comedia desde la Antigüedad. Definición asumida por Donato en el texto correspondiente y que básicamente se refiere a personajes, materia y desenlace: Inter tragoediam autem et comoediam cum multa imprimis hoc distat, quod in comoedia mediocre fortunae hominum, parvi impetus periculorum laetique sunt exitus actionum, at in tragoedia omnia contra, ingentes personae, magni timores, exitus funesti habentur; et illic in prima turbulenta, tranquila ultima, in tragoedia contrario ordine res aguntur; tum quod in tragoedia fugienda vita, in comoedia capessenda exprimitur; postremo quod omnis comoedia de fictis est argumentis, tragoedia saepe de historia fide petitur ${ }^{4}$.

C. Verardi previamente en la Historia Baetica, tanto en la dedicatoria como en los versos del prólogo, había planteado la dificultad de clasificar su pieza teatral, puesto que siendo sus personajes elevados (reyes, cardenales, consejeros) no tenía cabida dentro de los parámetros de la comedia. La relación exhaustiva de los personajes del teatro de Plauto le sirve para indicar su exclusión del drama: Neque audientur lenonum hic periuria, / Servorum technae, aut meretricum blanditiae; / Avara non usquam lena bic inducitur, / Milesve gloriosus, aut sycophanta impudens, / Edaxue parasitus, vel matrona impotens, / Paterve durus, aut amator cupidus, / Et reliqua, quae in Graiis nostrisque comicis / Spectata praebent voluptatem plurimam ${ }^{5}$.

En la obra todo es púdico y honesto y su final es feliz y dichoso, con lo cual tampoco, de acuerdo con la preceptiva dramática, tiene cabida de manera plena en la tragedia, cuya materia está plagada de los crímenes de los tiranos, las altanerías reales, la soberbia de los poderosos, sin presencia a su vez en la Historia Baetica. Algo similar ocurre con el desenlace de esta historia que concluye con la toma de la ciudad de Granada por los Reyes Católicos.

\footnotetext{
${ }^{2}$ Menéndez Pelayo, M. (1943), Los orígenes de la novela. Obras completas, t. XV, Madrid, p. 292, n.

${ }^{3}$ Verardi, Carlo et Marcelino, Fernandus servatus, ed. H. Thomas, Revue Hispanique 14 (1914), p. 437

${ }^{4}$ Donato, De com., IV-2.

${ }^{5}$ Verardi, Carlo et Marcelino, Historia Baetica. Prologus, (ed. M. D. Rincón), Granada, 1992, p. 154.
} 
Verardi era consciente de la novedad del tratamiento de la materia dramática, que le obliga a mezclar los dos géneros y advierte a los espectadores sobre falsas expectativas: Requirat autem nullus hic comoediae: / Leges ut obseruentur, aut tragoediae: / Agenda nempe est historia, non fabula ${ }^{6}$.

En definitiva, se enfrentaba al reto de representar una historia verídica, no una fábula inventada. Una historia auténtica y bien conocida, que ofrecía una poderosa carga de ejemplaridad. Es una forma didáctica de exponer la ejemplaridad de unos hechos realmente acontecidos, la ejemplaridad de una bistoria vera, no de una fabula ficta. Con el título mismo lo está confirmando: Historia Baetica.

La historia transformada en teatro y el teatro concebido -en ello es precursor del desarrollo posterior del drama escolar y hagiográfico- como un instrumento didáctico eficaz que dirigido a reyes y príncipes adquiere la naturaleza del speculum que a través del oído y de la vista muestra el camino que conduce a la fama imperecedera: Acta complexus sum, historiamque interlocutoribus personisque ita contexui atque distinxi, ut totam rem, ita uti gesta est, posset Populus Romanus non solum auribus percipere uerum etiam oculis intueri ${ }^{7}$.

La materia de sus dos dramas, historias reales, le obliga a enfrentarse a una situación mixta entre comedia y tragedia; no exactamente con el valor que Plauto da al término tragicomedia en los versos del Prologus del Amphitruo: Post, argumentum buius eloquar tragoediae. / Quid contraxistis frontem? quia tragoediam / Dixi futuram hanc? Deus sum; commutavero / Eandem hanc, si vultis; faciam ex tragoedia / Comoedia ut sit, omnibus eisdem versibus. /Vtrum sit, an non, vultis? Sed ego stultior / Quasi nesciam vos velle, qui divus sim. / Teneo quid animi vostri super hac re sit. / Faciam ut commixta sit tragicocomoedia, / Nam me perpetuo facere ut sit comoedia, / Reges quo veniant et dii, non par arbitror. I Quid igitur? quoniam huic servos quoque parteis habet / Faciam, sit, proinde ut dixi, tragicocomoedia ${ }^{8}$.

La gran diferencia con la interpretación plautina radica especialmente en su sentido moralizante: en la comedia de Plauto no se persigue la moraleja sino la risa, la diversión, que trasgrede el respeto a los personajes mitológicos, descendidos del Olimpo para mezclarse o actuar a tono con la galería de los personajes cómicos. Verardi cita el texto de Plauto para justificar su licencia formal y de esta manera se convierte también en paradigma de la libertad en el uso de los modelos clásicos del que da abundantes pruebas la comedia humanística.

\footnotetext{
${ }^{6}$ Íbidem, pp. 152-156.

${ }^{7}$ Carlo Verardi, Ad Raphaelem Riarium, Historia Baetica, (ed. M. D. Rincón), Granada 1992, p. 142.

${ }^{8}$ Plauto, Amph. 51-63.
} 
Pero si la licencia formal la extrae de Plauto, el sentido ético de la licencia lo haya en Lactancio: cum officium poetae sit in eo, ut ea, quae gesta sunt uere, in alias species obliquis figurationibus cum decore aliquo conuersa traducat ${ }^{9}$.

Verardi apoyándose en el carácter de vera historia de su obra, intuye algo que con anterioridad escasamente se había percibido: que lo "trágicocómico" permite una dramatización más dinámica de los hechos históricos, lo que será utilizado después en la escenificaciones de pasajes bíblicos, terencios cristianizados (con sus conexiones con el teatro jesuítico), y hasta las últimas consecuencias en las comedias historiales de Lope y lo bistories de W. Shakespeare.

Es una concepción de lo trágico-cómico que no pretende aplicar a un género, sino a una obra concreta, como lo hace Plauto. En esta situación Verardi sólo cuenta con el Amphitruo como precedente y aun así sigue manteniéndose una diferencia: es una historia verdadera que exige un tratamiento in alias species obliquis figurationibus cum decore aliquo ${ }^{10}$ como sugiere Lactancio. Sugerencia que le permite tejer la historia verdadera en diálogos de personajes, en texto representable para que el Pueblo Romano no sólo conozca de oídas sino que también compruebe con sus ojos lo ocurrido.

Entre la composición de la Historia Baetica y el Fernandus servatus debió de transcurrir poco más de un año. Durante ese tiempo C. Verardi reflexiona y madura los planteamientos expuestos en la primera pieza, que se resumían en la necesidad de compaginar las fabulas fictas del teatro y la nova et vera historia: Apporto non Plauti aut Neuii comoedias, / Quas esse fictas scitis omnes fabulas; / At nouam nobis ueramque fero historiam ${ }^{11}$.

La búsqueda de una forma dramática que sirviera de medio fiel para representar unos hechos bien documentados y contemporáneos fue algo original en el marco italiano del momento. Las producciones dramáticas de tema histórico y de carácter profano escritas en latín fueron escasas durante la Edad Media y el Renacimiento; cabría citar: la Ecerinis (c.1314) de Albertino Mussato; De casu Caesenae (1377) de autor inseguro; De captivitate ducis Iacobi (1470) de Laudivio dei Nobili; en la Cauteriaria de Barzizza, el Philodoxus de Alberti y la Chirsis de Aeneas Silvio, pero sólo se dan pinceladas de realidad, generalmente de toque autobiográfico. El esfuerzo de Verardi tiene claros precedentes en los intentos de algunos de estos humanistas de emular a los dos grandes comediógrafos latinos, Plauto y Terencio, en composiciones nuevas. Pero frente a estos precedentes la originalidad de Verardi se basa en

\footnotetext{
${ }^{9}$ Lactancio, Institutiones, I, 11, 24.

${ }^{10}$ Officium autem poetae in eo est ut ea quae vere gesta sunt, cum decore aliquo conversa transducat (Isidoro, Etimologiae, VIII 7, 10).

${ }^{11}$ Apporto non Plauti aut Neuii comoedias, / Quas esse fictas scitis omnes fabulas; / At nouam uobis ueramque fero historiam (Historia Baetica, Prologus, vv. 4-9)
} 
el respeto estricto a los hechos históricos en el caso de la Historia Baetica, en escoger acontecimientos fuera de Italia y en pretender exceder el espacio de la representación para erigir un testimonio válido para todos los pueblos cristianos. Verardi no se propuso crear caracteres pero tampoco los personajes, concretamente de la Historia Baetica, se diluyeron en lo meramente simbólico.

La rápida divulgación de las dos comedias humanísticas de C. Verardi es prueba de éxito inmediato en Europa debido a su temática, a intereses políticos $y$, en algunos casos, especialmente a la novedad literaria de sus planteamientos . En el caso de España, dos ediciones de incunables constatan su éxito y, como ya señalábamos, cabe suponer que la presencia del término tragicomedia en el título de la segunda edición de la Celestina (1502) sea el resultado de la lectura de los textos de Verardi aunque en su argumentación explícita el autor se base en la mezcla de elementos cómicos y trágicos referidos al inicio y el desenlace de la obra y no se valga de todos los argumentos utilizados por Verardi: El primer auctor quiso dar denominación del principio, que fue placer, llamóla comedia. Yo, viendo estas discordias entre estos estremos parti agora por medio la porfía y llaméla tragicomedia ${ }^{12}$.

Precisamente el que Rojas no preste atención, ni intente justificar la mezcolanza de lo narrativo con lo dramático, tan cuestionada por la crítica literaria posterior, ni argumente sobre la naturaleza mixta que ha impedido la adscripción de la Celestina al género de la novela o de la comedia humanística, reafirma aun más la posibilidad de la dependencia de Verardi en cuanto a la utilización del término tragicomedia que frente a esa problemática podría tener un valor secundario, a pesar de que con su uso el autor la haya adscrito al teatro.

En cualquier caso, el nombre de tragicomedia quedó en la literatura española del siglo XVI a partir de La Celestina: Gil Vicente, que en tantas cosas fue tributario de ella, llamó tragicomedias a una sección entera de sus obras. En 1539 se publicaba en Burgos la Tragicomedia alegórica del Paraíso y del Infierno refundición castellana de una de las Barcas del mismo Gil Vicente. Una de las piezas de la Turiana, atribuídas a Juan de Timoneda, lleva el título de Tragicomedia Filomena. En la numerosa serie de las Celestinas sólo la de Sancho Muñón se titula Tragicomedia de Lisandro y Roselia.

La Historia Baetica y el Fernandus servatus resultaron también un estímulo para composiciones de carácter histórico, representadas, a veces, para celebrar acontecimientos políticos o militares. Siguieron el modelo de historia dramatizada Pedro de Lerma con su Comedia o Farsa sobre la figura del cardenal Cisneros (Alcalá, 1508) hoy perdida. B. Barrientos habla de su tragicocomedia De Illiberitanorum maurorum seditione sobre la sublevación de los moriscos de la Alpujarra (Salamanca, 1569). También perdida la comedia

${ }^{12}$ Rojas, F. de, La Celestina, (ed. M. Criado), Madrid, 1976, p. 17. 
o drama de Antonio $\mathrm{Pi}^{13}$ dedicada a $\mathrm{D}$. Juan de Austria por la victoria de Lepanto y que, al parecer, fue representada por sus alumnos en Barcelona. En Barcelona debió de imprimirse en 1543 la Tragedia Delphinus de Francesc Satorres.

En definitiva, a partir de F. de Rojas, ya durante el s. XVI, la palabra tragicomedia está asociada a la Celestina, pero es preciso tener presente que la historia de la literatura está en deuda con el autor de la Historia Baetica y el Fernandus Servatus, que supo reutilizar el término plautino, justificó su aplicación y lo divulgó a finales del s. XV.

${ }^{13}$ Torres Amat, F., Memorias para ayudar a formar un Diccionario Critico de los escritores catalanes, Barcelona, 1836. Facsímil, Barcelona /Sueca, Curial, 1973. 